\title{
Modelling the drivers of a widespread shift to sustainable diets
}

\author{
Sibel Eker ${ }^{a, *}$, Gerhard Reese ${ }^{b}$, Michael Obersteiner ${ }^{a}$ \\ a International Institute for Applied Systems Analysis (IIASA), Schlossplatz 1, A-2361 Laxenburg, \\ Austria \\ ${ }^{\mathrm{b}}$ University of Koblenz-Landau, Department of Social, Environmental and Economic Psychology, \\ Fortstraße 7, 76829 Landau, Germany \\ *Corresponding author, eker@iiasa.ac.at
}

\section{Abstract}

A reduction in global meat consumption can significantly reduce the adverse environmental effects of the food system, but it would require widespread dietary changes. Such shifts to sustainable diets depend on several behavioural factors, which have not yet been addressed in relation to the food system. This study links a behavioural diet shift model to an integrated assessment model to identify the main drivers of global diet change and its implications for the food system. The results show that the social norm effect - for instance the extent of vegetarianism in the population that accelerates a further switch to a vegetarian diet - and selfefficacy are the main drivers of widespread dietary changes. These findings stress the importance of value-driven actions motivated either by intrinsic identity or by group dynamics over health and climate risk perception in steering diet change dynamics.

\section{Main}

Lifestyle change is considered an important demand-side measure to mitigate climate change ${ }^{1,2}$. Lowering energy demand and the greenhouse gas (GHG) emissions of food consumption with climate-friendly lifestyle choices can be key to achieving $1.5^{\circ} \mathrm{C}$ pathways $\mathrm{s}^{3,4}$. Besides issues related to land use and GHG emissions, the food system damages natural ecosystems ${ }^{5}$ and pushes the Earth towards the planetary boundaries for freshwater use, deforestation, and ocean acidification ${ }^{6,7}$. Several studies have demonstrated that lowering global meat consumption can significantly mitigate the adverse environmental effects of the global food system ${ }^{8,9,10,11,12}$.

Diet change scenarios explored in previous studies, which are based on stylized diets or average consumption values, are promising to alleviate environmental degradation. Yet, they are difficult to achieve due to the scale of behavioural change required. For instance, if the world's average diet became flexitarian by 2050 , meaning that red meat consumption is limited to one serving per week and white meat to half a portion per day, the GHG emissions of the agriculture sector would be reduced by around $50 \%{ }^{12}$. Currently, $1.8 \%$ of daily calories are obtained from red meat (beef and lamb) in the world's average diet ${ }^{13}$. In a flexitarian diet, one serving of red meat per week constitutes only $0.5 \%$ of daily caloric intake. The difference is small, but it would require billions of consumers to change their diets for a global change. 
Red meat consumption has been declining in several countries including the USA, the UK, and Germany ${ }^{13}$. Market research in the UK shows that around one third of consumers identify themselves as meat reducers ${ }^{14}$. Consumers, however, also resist diet change due to reasons such as taste preferences and traditions ${ }^{15}$, a lack of awareness about the link between climate change and food consumption ${ }^{16}$, or ideological beliefs about human-animal relations ${ }^{17,18,19}$. Because of this resistance, the global consumption levels that provide environmental benefits may not be reached in practice. Therefore, it is important to widen the scenario space - especially those generated by integrated assessment models - into behavioural mechanisms that trigger diet change, and to identify the factors that stimulate rapid and significant climate mitigation actions $^{2}$.

This study investigates the factors that steer diet changes towards low meat consumption by linking a model of human behaviour to an existing integrated assessment model. In particular, we extended the FeliX model ${ }^{20,21,22}$ with population segmentation for dietary choices, and we modelled the shifts between these segments based on main psychological theories that are used to explain individuals' environmental actions. We examined the environmental impact of a large number of diet shift scenarios, and identified the behavioural model elements that are most critical in obtaining widespread diet shifts.

\section{Modelling diet change}

We adopted a feedback perspective on climate mitigation action to conceptualize diet shift dynamics as such feedbacks between physical and human systems poses an uncertainty that is similar in magnitude to the physical uncertainty of global temperature change ${ }^{23}$. In particular, we considered two main feedback mechanisms (Fig. 1) based on two complementary theories of psychology. According to the Theory of Planned Behavior ${ }^{24}$, behavioural intentions are formed by perceived behavioural control or self-efficacy, subjective social norms, and attitude, which basically refers to whether the suggested behaviour is evaluated positively or not. Diet change due to social norms forms a positive feedback loop, since a higher number of vegetarians shifts the norm, which further stimulates diet change behaviour. According to the Protection Motivation Theory ${ }^{25}$, actions are determined by threat appraisal, an individual assessment of the severity of a threat, and coping appraisal - the extent to which an individual can, and is willing to, cope with the threat. This theory has been used to model emission behaviour ${ }^{23}$ by linking threat appraisal to climate events.

In the context of diet change, combined with the global food system represented in the FeliX model, threat appraisal of climate change risk forms a negative feedback loop, where the diet shift to vegetarianism leads to lower emissions, fewer climate events, and a lower threat. Public risk perception is argued to depend on various factors such as social values, media coverage, self-interest and the direct observation of risk, rather than purely quantitative risk metrics ${ }^{26}$. Following previous modelling studies ${ }^{23}$, we assume that climate events observed and retained in public memory represent the perceived climate risk, since they refer to direct public experiences and media coverage.

Health risks attributed to high red meat consumption is another important concern that motivates people to change their diets ${ }^{27}$. The health benefits of sustainable diets have been 
widely discussed ${ }^{10,28,29,30}$, and a healthy and sustainable diet is quantitatively defined based on an integrated framework that combines health effects and the planetary boundaries of the food system $^{31}$. Sustainable diets, such as a flexitarian diet with one serving of red meat per week, are concluded to have the potential to reduce deaths by 10.8-11.6 million per year ${ }^{31}$. Following this, we included health risk in the model as a driver of diet change behaviour. We modelled perceived health risk endogenously in relation to average red meat consumption.

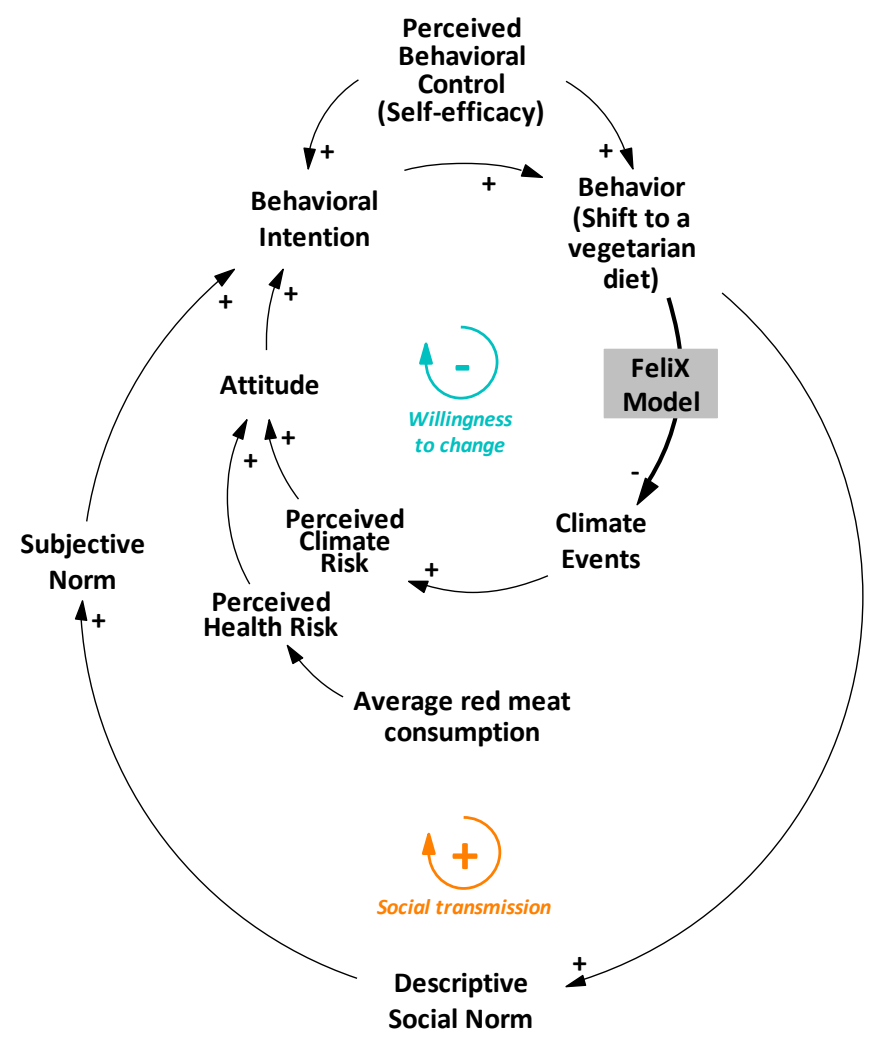

Fig. 1. Conceptual framework of the diet change model. The figure illustrates the behavioural framework underlying the diet change model. The arrows represent a causal relation between two factors, and the polarity of an arrow indicates whether the relation is positive or negative. Diet change behaviour (action) is determined by behavioural intention, as well as by self-efficacy, response efficacy, and response cost. Intentions are formed by subjective norms - an individual's perceptions of the social norms and attitude towards diet change - whether it is perceived as good or bad. While social norms are affected by the spread of the behaviour, thus forming the positive social transmission loop, attitudes are driven by the perceived threat of climate events, forming the negative willingness to change loop. Perceived health risk attributed to red meat consumption is another factor that affects attitude towards diet change.

The model is formalized with a public segmentation and innovation diffusion approach ${ }^{32,33}$. The population is divided into two - meat-based diet followers and vegetarians. The flows, that is, diet switches between the two groups are modelled according to income change, since increasing income leads to higher meat consumption, especially in developing countries ${ }^{34}$, and the behavioural factors outlined in Fig. 1. Population heterogeneity is taken into account in terms of age, gender, and education level. The global food demand resulting from these population dynamics is reflected on the land use and climate modules of the FeliX model. Following Beckage et al. ${ }^{23}$, randomly generated climate events driven by global temperature 
change are used to compute the perceived climate threat. (See Methods for a detailed model description.)

Each population segment is associated with a reference diet composition to consider demand changes for different food categories. To add variety to diet compositions beyond a reference meat-based and a reference vegetarian diet, we consider four diet composition scenarios where each population segment (meat-eaters and vegetarians) was associated with a different diet type shown in Table 1. For instance, Scenario 3 assumes that all meat-eating population will be flexitarian by 2050; and all vegetarian population will actually be vegan by 2050 . (The compositions of these diet types are described in Supplementary Error! Reference source not found..) Behavioural factors such as self-efficacy or response efficacy can play different roles in these diet composition scenarios. For instance, self-efficacy for switching from meat-eating to a vegetarian diet may differ from switching to a vegan diet. However, to our knowledge, there is currently no information and data on these differences in the literature. Therefore, we quantify the behavioural factors equally in these four diet composition scenarios, yet consider potential differences among the four scenarios in the uncertainty analysis.

Table 1. Diet composition scenarios. The table shows the diet composition associated with the two population segments in four diet composition scenarios. In scenarios 1, 2, and 3 the diet composition is assumed to change gradually from the reference diet type in 2020 to the given diet type in 2050. The numbers in parentheses refer to the percentage of daily calories taken from animal products in each diet type.

\begin{tabular}{l|l|l} 
Scenario & Meat-eater's diet & Vegetarians' diet \\
\hline Sc0_Reference & Reference meat-based diet $(17.2 \%)$ & $\begin{array}{l}\text { Reference lacto-ovo vegetarian diet } \\
(9 \%)\end{array}$ \\
\hline Sc1_Healthy+Ref & $\begin{array}{l}\text { Healthy eating guidelines by } 2050 \\
(14 \%)\end{array}$ & Reference lacto-ovo vegetarian diet \\
\hline Sc2_Healthy+Vegan & Healthy eating guidelines by 2050 & Vegan diet by 2050 (0\%) \\
\hline Sc3_Flexitarian+Vegan & Flexitarian by 2050 (11.7\%) & Vegan diet by 2050
\end{tabular}

\section{Results}

\section{Environmental impact of diet change}

23 To account for the uncertainty in behavioural parameters, we simulate the model 10,000 times, each with a unique combination of the parameter values sampled from their uncertainty ranges (Supplementary Table 3). The dynamic simulation results show a wide range for the Percentage of Vegetarians in the total population especially towards 2100. It is however mostly around $20 \%$ (Fig. 2a). Both the reference simulation and the uncertainty space demonstrate a higher percentage of vegetarians in the reference diet composition scenario compared to the other diet composition scenarios. This result can be attributed to climate and health risk, which are higher in the reference diet composition scenario and stimulate more shifts to vegetarianism. GHG emissions from agriculture and land use also show a wide range of dynamics (Fig. 2b). In the reference diet composition scenario (Scenario 0), the emissions vary between 10 and 15 
$\mathrm{GtonCO}_{2} \mathrm{eq}$ in 2100. This implies that, despite increasing population and food demand, the emissions can be brought back to current values (10.2 $\mathrm{GtonCO}_{2} \mathrm{eq}$ in 2010) by 2100 , even with the current average compositions of meat-based and vegetarian diets, if a significant shift to vegetarianism occurs. Still, more significant emission savings are obtained in the low-meat diet composition scenarios.

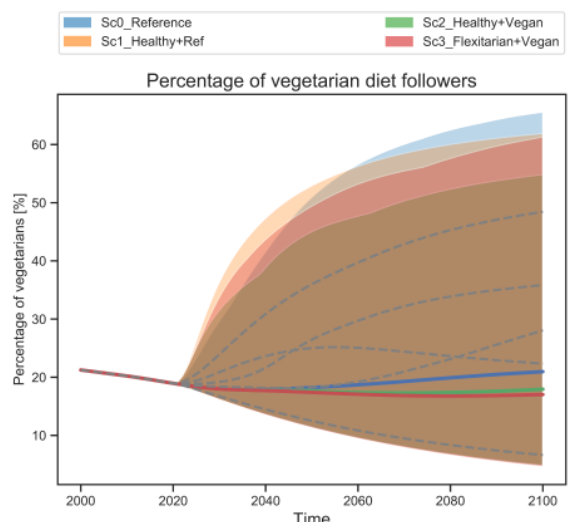

(a)
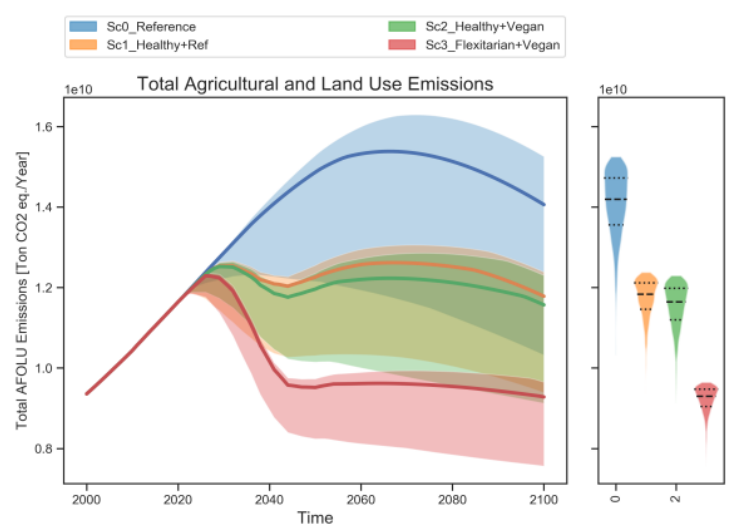

(b)

Figure 2: Dynamic simulation results for (a) the percentage of vegetarian diet followers in the total population, (b) total agricultural and land use emissions. The bold coloured lines show the reference simulation results for each diet composition scenario, while the shaded area around them depict the uncertainty space generated by the behavioural parameters with $\pm 50 \%$ uncertainty around their reference values. The violin plots on the right-hand side of each plot show the density distribution of simulation results in 2100 with the $25^{\text {th }}, 50^{\text {th }}$, and $75^{\text {th }}$ percentiles marked. While the range of percentage vegetarian population is quite wide, the median value is below $20 \%$ in every diet composition scenario. Emissions from the agriculture and land use sector also show a wide variety with respect to the spread of vegetarianism and diet composition scenarios. Although there are a few cases where the increasing pattern of emissions is ceased even in the reference diet composition scenario, the highest reduction potential is in the third diet composition scenario.

Fig. 3 provides a static look at these scenarios in 2050, considering the pairwise relation of key environmental variables. By 2050, significant reductions can be obtained in the Total Agriculture and Land Use Emissions compared to the expected business-as-usual values ( 15 $\left.\mathrm{GtonCO}_{2} \mathrm{eq}\right)$. These significant reductions however mostly apply in cases where not only vegetarianism becomes widespread, but meat-eaters also reduce their consumption (Fig.3e and f). Even though the vegetarian population percentage rises above $40 \%$, emission savings of the reference diet composition scenario (S0) are far below the scenarios where meat-eaters also reduce their consumption (e.g., S3). This finding indicates that drastic shifts by a small group are not sufficient to reap the environmental benefits of diet change. To significantly reduce the environmental degradation caused by the food sector, widespread changes across the global population are required, although the extent of such changes is not maximal.

Most simulation results show (Fig. $3 \mathrm{c}$ and k) high cropland use in the medium meat consumption scenarios ( $\mathrm{S} 1, \mathrm{~S} 2$ ) compared to the reference diet composition scenario (S0). This is due to the increased demand for plant-based food such as vegetables and fruits, while the demand for grains declines. However, since the meat demand is much lower in Scenario 3, cropland use becomes distinctively low. This can be explained by low grain production outweighing the high production of other crops. In other words, although Scenario 3 also results in high demand for vegetables, fruits, and other crops, the feed demand from the meat sector is 
much lower. Therefore, the decreasing grain production for feed balances out the increasing production of other crops, and cropland use results in lower values than all other diet composition scenarios.

4 Different diet compositions also result in distinctive scenarios for fertilizer application. Low meat demand in Scenario 3 leads to low grassland use, and reduces pressure on agricultural land. A lower pressure on agricultural land availability reflects on managerial practices and leads to fertilizer application volumes that are much lower than in the other three scenarios (Figure 31 and p). Even though the uncertainty space created by diet shift dynamics is large, it still cannot create overlaps between diet composition scenarios. In other words, even if a large percentage of the population becomes vegetarian, nitrogen use cannot be reduced as much as it can be in the case of meat-eaters reducing their consumption.

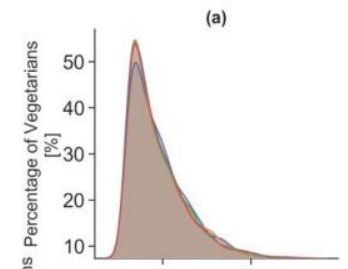

(e)
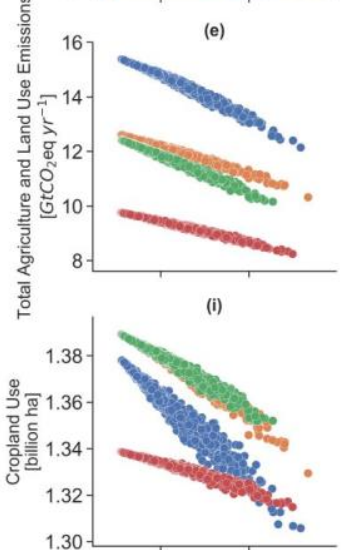

$(\mathrm{m})$

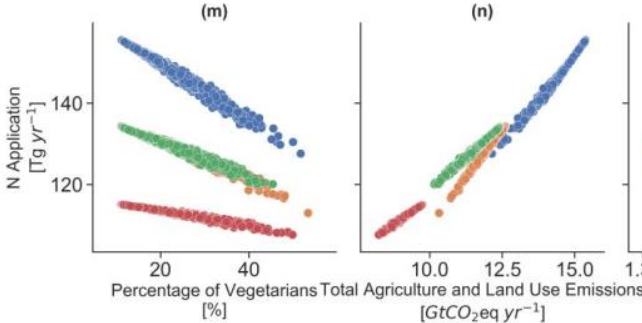

(b)

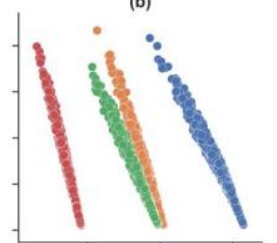

(f)

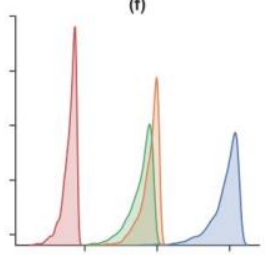

(i)

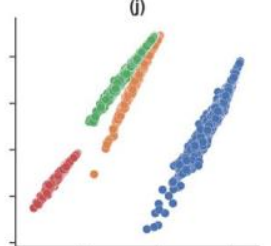

$\left[\mathrm{GtCO}_{2} \mathrm{eq} y \mathrm{r}^{-1}\right]$ (c)

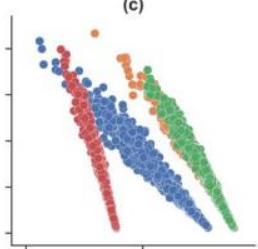

(g)

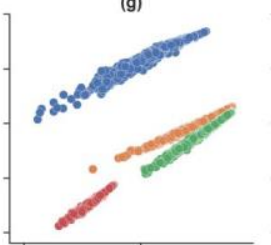

(k)

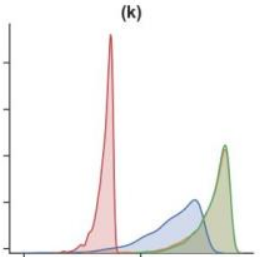

(o)

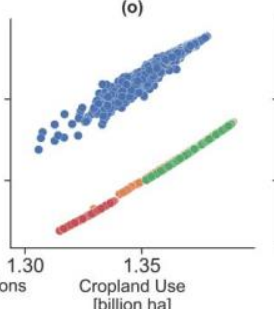

(d)

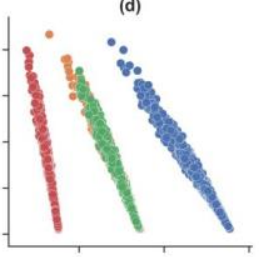

(h)
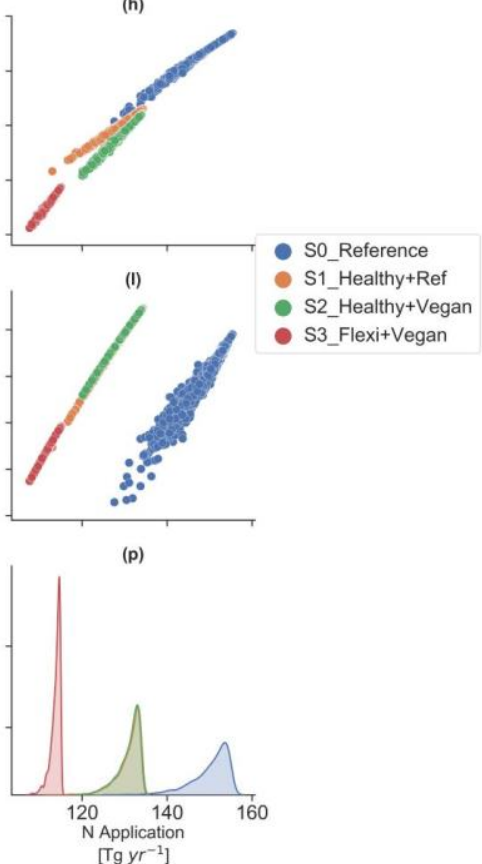

Fig. 3. Environmental impact of diet change scenarios in 2050. The figure shows the results of 10,000 model simulations in 2050 for the Percentage of Vegetarians in the total population, Total Agricultural and Land Use Emissions, Cropland Use, and commercial Nitrogen (N) Application in agriculture. Each plot shows the respective results for a pair of these four indicators, except the diagonal cells that show the density distribution of the indicator in the $\mathrm{x}$-axis. The colours refer to the diet composition scenarios. Despite a wide range, the vegetarian population is less than $20 \%$ in the majority of simulations. Emissions are almost linearly related to the vegetarian population, and can be below the 2010 values $\left(\sim 10.2 \mathrm{GtCO}_{2}\right)$ only in the third diet composition scenario (S3). Cropland Use is higher than the reference in the medium meat consumption scenarios (S1 and S2), yet lowest in the low-meat scenario (S3). 


\section{Drivers of diet change behaviour}

2 We use two complementary approaches to investigate the factors that could drive a widespread

3 diet change. The first approach answers the question "Which behavioural factors cause the 4 highest sensitivity in the vegetarian percentage of the global population?", whereas the second

5 one addresses, "Which factors are associated with a high spread of vegetarians in the global 6 population?"

7 First, we identify the model parameters that contribute most to the variance in model outcome in 8 each diet composition scenario based on a Global Sensitivity Analysis and Sobol indices (See

9 Methods). According to the results for the reference diet composition scenario (Fig. 4), the 10 parameter $x 0$ social norm of the young population (ages 15-44) contributes most to the variance of model output. This parameter is the inflection point of the logistic function that defines the relationship between the descriptive social norm (percentage of vegetarians in each demographic group) and the diet change behaviour (Supplementary Figure 3). In other words, it represents the spread of vegetarian diet where the slope of the logistic function that define the social norm effect is steepest, and consequently the feedback effect is strongest. This finding demonstrates that diet change behaviour is influenced most by a high public responsiveness to initial changes in the vegetarian population. The difference between the first-order (S1) and total (ST) Sobol indices of $x 0$ social norm indicates that its interaction with other model parameters causes more variation in the output. This can be attributed to the amplifying effect of social norms once the diet change attitude is set with health and climate risk perception.

The second most influential parameter is the self-efficacy multiplier of the females. Self-efficacy plays a dual role in diet change both on intention and action, and the self-efficacy of females is assumed to be higher than that of males. Therefore, this finding emphasizes the dual and conclusive role of self-efficacy once the attitude is set according to risk and social norms. The parameter in the third rank is normal fraction intended to change diet. This parameter represents the base fraction of meat-eaters who intend to switch to a vegetarian diet, without the effects of social norm, risk perception, self-efficacy, and response-efficacy. Both these parameters contribute more to the variance in interaction with other factors (ST).

The following parameters in the Sobol sensitivity ranking relate to how quickly the young population responds to health risks ( $x 0$ health risk attitude), the extent of responses by the young population to social norms ( $L$ social norm), and the response efficacy of secondary education graduates. In the socio-psychological modelling framework we use, the young population is already more inclined to diet change due to a higher susceptibility to social normsa higher responsiveness to health risks. Therefore, the high sensitivity of the model to the parameters representing youth emphasizes the potential of using low hanging fruit as leverage points for diet change. Regarding the response efficacy, secondary education graduates constitute the largest demographic group according to educational attainment level. Therefore, a high sensitivity to this parameter highlights the importance of assuring this large demographic group about the positive impact of diet change. The factors related to climate risk perception $(L$ and $x 0$ risk attitude) are ranked after response efficacy in terms of their contribution to variance. 
When the sensitivity indices are calculated in 2100 , the top factors remain the same. However, the sensitivity indices of these top parameters, especially $x 0$ social norm, decline and those of lower rank parameters, such as the ones related to climate risk perception ( $L$ risk attitude) and social norms among the middle-aged population ( $L$ social norm [45-49]), increase. Hence, contributions to the model output uncertainty from low-ranking factors do increase in the longterm. Furthermore, the difference between S1 and ST is tapered in the long-term when the diet shifts approach saturation (Fig. 2a), implying that parameter interactions are not as significant as before when compared to individual contributions to variance.

When the sensitivity indices are calculated in different diet composition scenarios, the results (Supplementary Figure 11-13) are similar. Simulation results show similar dynamics and variation for the spread of vegetarianism in the four diet composition scenarios (Fig. 2a). Therefore, this finding of the sensitivity analysis indicates that the model parameters causing the variation are also similar across the diet composition scenarios.

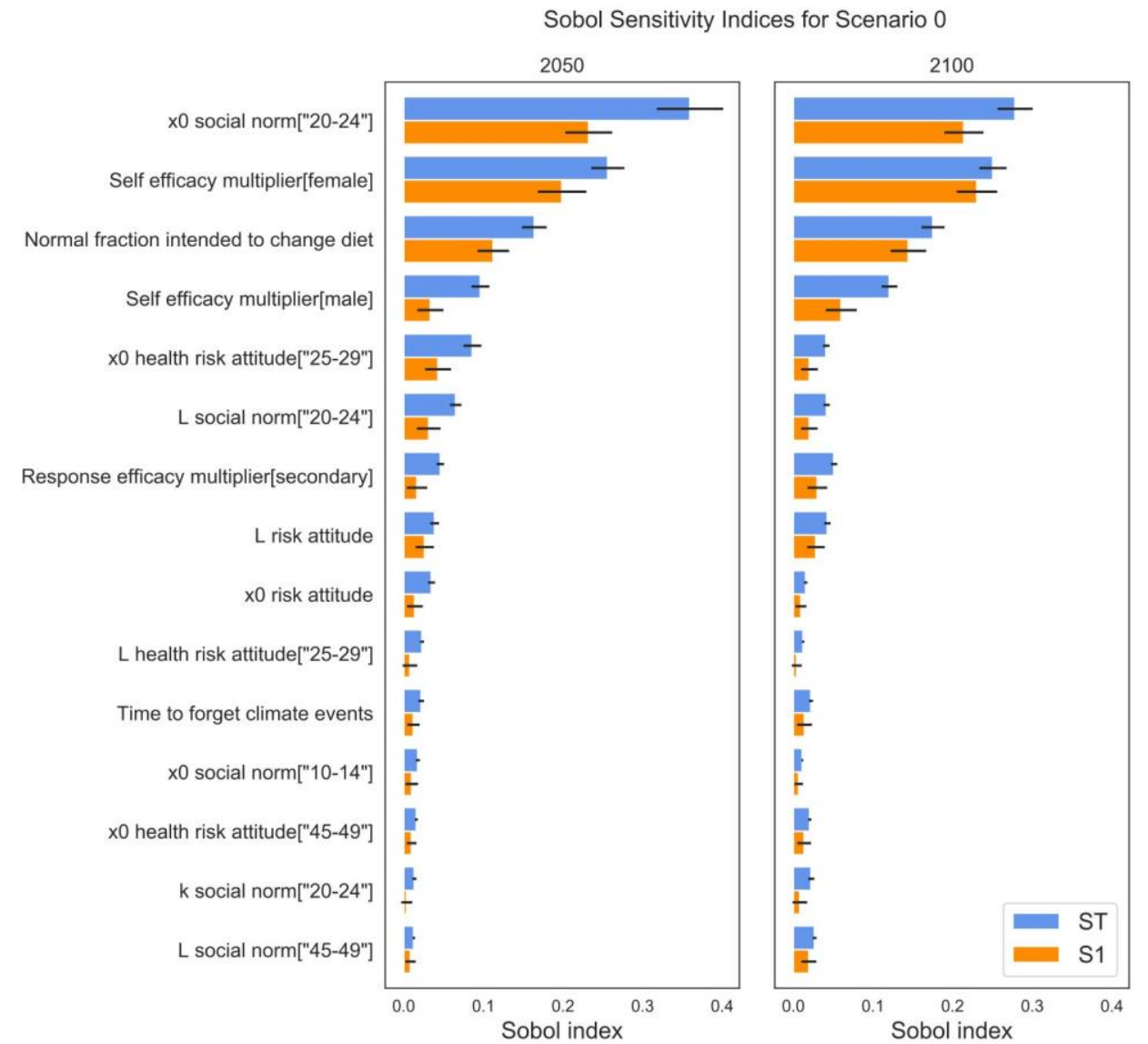

Fig. 4. Sobol sensitivity indices for the Percentage of Vegetarians in 2050 and 2100 for the reference diet composition scenario. The figure shows the first-order (S1) and total (ST) Sobol indices of the model inputs, that is, the contribution to the variance of Percentage of Vegetarians in the model output. The higher the Sobol index, the larger the variance caused by an input. The model inputs with less than $1 \%$ contribution (Sobol index smaller than 0.01) are not displayed in this figure. First order Sobol indices (S1) refer to the individual contribution of a parameter to the output variance, whereas total Sobol indices (ST) refer to the contribution of a parameter to the output variance in interaction with all others. The difference between S1 and ST indicates the importance of parameter interactions. The whiskers show the $95 \%$ confidence interval. The parameter ' $x 0$ social norm ["20-24"]' that defines the rapidness of the young population's response to social norms is the most influential, followed by female self-efficacy. The 
parameters in high ranks do not differ between 2050 and 2100. The definitions of the parameters can be found in Supplementary Table 3.

The second approach we follow to investigate the drivers of diet change is a scenario discovery method called the Patient Rule Induction Method (PRIM) ${ }^{35,36}$. With this data mining method, we identify the model inputs associated with widespread diet shifts. In other words, we find the behavioural factors that distinguish the simulations (cases) where Percentage of Vegetarians is higher than the $3^{\text {rd }}$ quartile of its uncertainty range. The results are similar to those obtained by the global sensitivity analysis, whether it is in the reference diet composition scenario (Fig. 5a and $5 \mathrm{~b}$ ), or in the scenario where meat-eating and vegetarian population follow flexitarian and vegan diets, respectively (Fig. 5c).

Three model parameters are repeatedly among the most distinguishing factors as in the sensitivity analysis results. First, the parameter $x 0$ social norm falls in the lower half of its uncertainty range in the cases of interest. As explained before, this parameter defines the scale of vegetarianism in the young population that triggers a rapid behavioural response. The second distinguishing factor is the female self-efficacy multiplier, followed by normal fraction intended to change diet. The number of climate events that trigger a rapid diet change response ( $x 0$ risk attitude) also appears among the distinguishing factors, yet with a relatively high quasi p-value. Hence, climate risk is considered a relatively less important factor.

The additional factors that distinguish the high-vegetarianism scenarios depend on the time frame and the diet composition scenario. For instance, in the reference diet composition scenario (S0), how quickly the young population responds to increasing health risk ( $x 0$ health risk attitude) is one of the distinguishing factors in 2050 (Fig. 5a), while it is replaced by the time to forget climate events, that is, the average duration of climate events in public memory, in the long-term (Fig. 5b). In the combination of flexitarian and vegan diet compositions (S3), which implies a lower health risk, not only the responsiveness of the young population to social norms but also the extent of response ( $L$ social norm) emerges as a factor affecting diet shifts (Fig. 5c). Furthermore, the extent of response to health risk by the young population ( $L$ health risk attitude) is another important factor associated with widespread diet change in this diet composition scenario.

When the scenario discovery analysis was repeated for other diet composition scenarios, the results varied (Supplementary Figure 15-18). Still, as a general pattern, the first three parameters ( $x 0$ social norm, normal faction and female self-efficacy) remained the same. Furthermore, the responsiveness of the young population to increasing health risk ( $x 0$ health risk attitude) was among the most distinguishing factors in 2050 regardless of the diet composition scenario, while the factors affecting the climate risk perception and response efficacy of the secondary education graduates appeared more important in the long term. In the low-meat scenario (S3), however, although many factors are identified by the scenario algorithm as influential on diet shifts, they were not highly restricting. In other words, none of the factors except the three parameters were distinctively influential on widespread diet shifts. This can be attributed to already low meat demand in this scenario, hence the lack of health effects to trigger diet change response. 


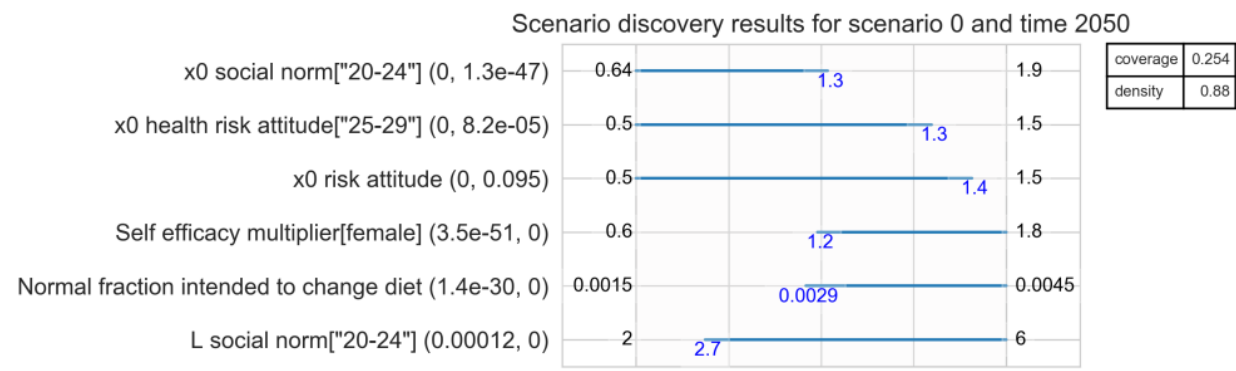

(a)

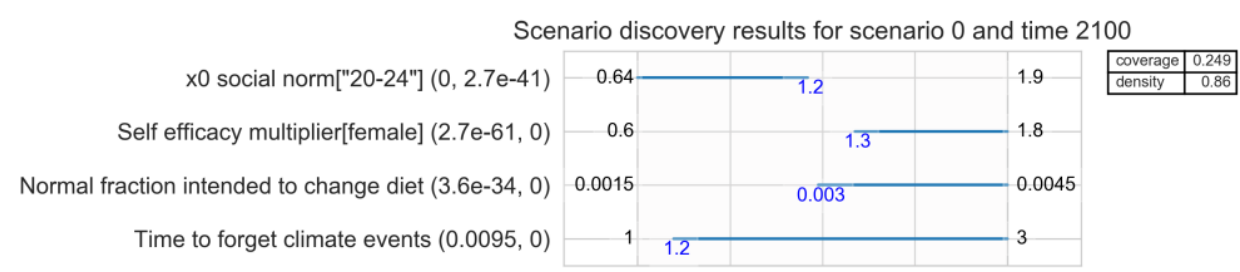

(b)

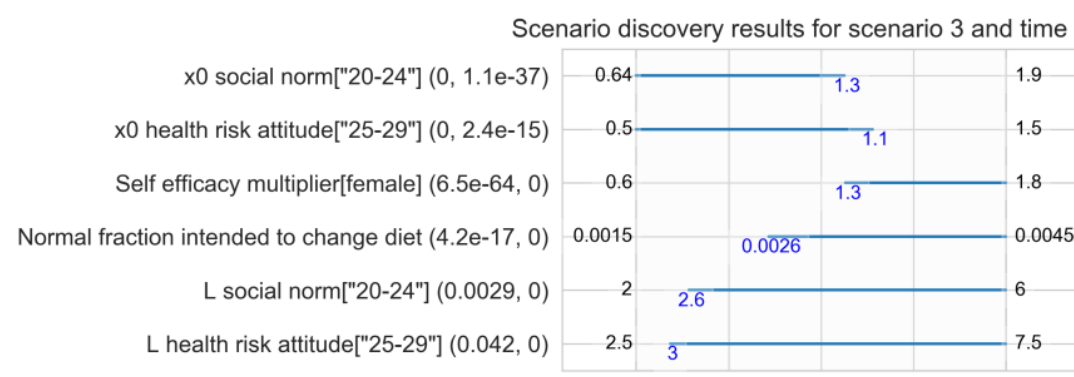

\section{0}

(c)

Fig. 5. Scenario discovery results for Percentage of Vegetarians (a) for the reference diet composition scenario S0 in 2050, (b) for the reference diet composition scenario S0 in 2100, (c) for the combination of flexitarian and vegan diet compositions in S3 in 2050. The figure shows the model parameters that distinguish the simulations where Percentage of Vegetarians is higher than its $3^{\text {rd }}$ quartile. The length of each line represents the subset of the corresponding parameter's uncertainty range leading to these high-vegetarianism scenarios. The smaller the subset, the more distinguishing a parameter is. The numbers at the two ends of the grey shaded area are the lower and upper boundaries of the entire uncertainty range of a parameter, while the numbers in blue at the end of the lines refer to the identified subset boundary, that is, box limits. The values in parentheses next to parameter names show the quasi pvalues for the lower and upper end of the identified box appearing in the results by coincidence. The smaller its pvalue, the more certain it is that a parameter is distinguishing the simulations of interest. The spread of vegetarianism that trigger a rapid behavioural response (x0 social norm) for the young population, self-efficacy of females, and the normal fraction of population that intend to change their diet are repeatedly among the most distinguishing factors.

\section{Discussion}

14 Behavioural change, especially in the food consumption context, has been cited as a highly promising climate change mitigation strategy. However, significant benefits would require substantial and widespread diet shifts. This exploratory modelling study shows that such substantial shifts, for instance a vegetarian population that constitutes more than $40 \%$ of the total, are obtained in a few simulation cases with optimistic assumptions. Adopting an uncertainty-oriented approach due to the lack of data, this study identified the factors that lead to widespread diet shifts. Within the specified modelling framework, diet shift behaviour is most sensitive to social norms and self-efficacy, while the factors related to health and climate risk perception are relatively less influential. 
More specifically, widespread diet changes were observed in the simulations if the young population's response (ages 15-44) to social norms is rapid even when the spread of vegetarianism in this demographic group (descriptive norm) is low. Several scientists in the climate change arena have acknowledged that people's beliefs and subsequent actions are shaped by the values endorsed by their peer group, not by scientific facts ${ }^{37,38,39}$. Our finding on the social norm effect resonates with those, and emphasizes the role of social norms beyond the factual health and climate risk.

Self-efficacy, primarily of females, is another important factor in triggering diet change dynamics, and is attributed to its dual role on both intentions and actions. Self-identity, encompassed by the self-efficacy factor in this study's modelling framework, has long been considered a key lever to stimulate pro-environmental behaviour ${ }^{40,41,42,43}$. However, recent findings show that self-identity does not necessarily lead to repeated pro-environmental behaviour, and it can cause negative spill over effects ${ }^{43}$. Therefore, self-efficacy should be taken with caution as an intervention lever.

The findings about the self-efficacy of females and the social norm and risk response of the young population highlight the importance of demographic groups who already have a high tendency to change their diet behaviour. However, response efficacy, i.e. people's belief about whether their actions would really make an impact or not, is an exception. Although response efficacy is positively related to education level, the response efficacy of the secondary education graduates, not the tertiary, is more effective on diet change dynamics. This is because the secondary education graduates are the largest population group according to educational attainment level, hence their high response efficacy triggers widespread shifts. In addition, more recent research suggests that collective-efficacy - the belief that one's group is capable of achieving change - may be a more important predictor of pro-environmental actions ${ }^{44,45}$.

The model-based scenarios explored in this study show that diet composition has a bigger impact on the food system's environmental footprint compared to the extent of diet shifts triggered by behavioural factors. Even if up to $40 \%$ of the global population turns vegetarian, the environmental benefits of diet change may not be fully observed as long as the remaining meat-eaters consume the current averages. Therefore, instead of drastic shifts by a small group, population-wide changes are required, even though the extent of such changes is not maximal. The model results also show that lowering meat consumption can lead to nonlinear environmental impacts. Particularly, cropland use is higher in the scenarios with medium meat consumption (healthy diet) than in the high meat consumption scenario (reference), although it is much lower in the flexitarian diet composition scenario with the lowest meat consumption. This nonlinearity is due to the decrease in feed demand outweighing the increase in plant-based food demand, and stresses the importance of taking such nonlinearities into account.

This study's scope is limited to income, social norms, climate and health risk perception, as well as other psychological factors such as self-efficacy and response efficacy as the drivers of diet change behaviour. Demographic heterogeneity affecting these factors is included in terms of gender, age, and education level, and population dynamics are investigated in a globally aggregate manner. There are however several other factors and different dimensions of 
heterogeneity. For instance, public risk perception is rooted in social and cultural values transmitted by social interactions ${ }^{26}$, therefore objective metrics used for risk communication are not expected to be highly effective. Similarly, the differences in climate risk perception are shown to stem from cultural and political world-views in the US, not solely from science literacy ${ }^{39}$. Furthermore, in countries like Finland and Scotland, empirical studies demonstrated that cultural values and traditions are often a barrier, or strengthen the perception of barriers to lowering meat consumption ${ }^{16,46}$. Therefore, local dynamics can develop differently than the global dynamics explored in this study. In future studies, the modelling framework developed in this study can be extended to capture cultural values and world views within the limits of computational modelling, and can be customized to represent local settings, e.g. individual countries, where the understanding of values and empirical data is richer.

Modelling diet shifts inevitably involves several uncertainties due to lack of data, or ambiguities and subjectivities associated with human behaviour. Therefore, we adopted an uncertaintyoriented approach in this study, with a large number of scenarios covering a wide uncertainty space. We used the model outcomes to derive insights about the interlinkages and feedback mechanisms in the food system, and to diagnose the influential factors. Based on these findings, this study can be used to prioritize issues and factors to guide future model development and data collection efforts given the urgency of need for further research in this area. It can subsequently assist the formulation of potential policy interventions based on the most influential factors. For instance, empirical studies can focus on quantifying the relationship between social norms and diet change behaviour, this quantification can further feed into models to explore the long-term effects of diet shifts and different intervention mechanisms.

To systematically examine how an accelerated behaviour change can be achieved for climate change mitigation, research communities increasingly stress the importance of explicitly including human behaviour in integrated assessment models ${ }^{2,47,48}$. This study presents an example in the context of diet change towards low meat consumption. The modelling framework used in this study combined prominent theories from psychology on environmental action, and from management science on innovation diffusion. It exemplifies including demographic heterogeneity to model lifestyle changes. Therefore, it is generalizable and transferrable to other behaviour change domains that can be included in integrated assessment models.

\section{Methods}

\section{Model description}

\section{Overview of the FeliX model}

In this study, consumer actions and preferences for dietary shifts were modelled as an extension to an existing integrated assessment model, the FeliX Model ${ }^{20}$. The FeliX Model consists of eight sectors, namely Economy, Energy, Carbon Cycle, Climate, Biodiversity, Water, Population, and Land Use. The model captures the core physical and anthropogenic mechanisms of global environmental and economic change within and between these eight sectors. The Felix 
Model has been used to assess the socio-economic and environmental impacts of earth observation improvement ${ }^{49,50}$, to explore emission pathways when microalgae is used as a feedstock in livestock production ${ }^{21}$, and to analyse global energy and land use emission scenarios for realistic climate change mitigation pathways ${ }^{22}$.

\section{Diet change model}

\section{Psychological framework for diet change}

The diet shifts extension to the FeliX Model was based on two complementary theories of psychology (Fig. 1): The Theory of Planned Behaviour (TPB $)^{24}$ and the Protection Motivation Theory (PMT) ${ }^{25,51}$. Both theories were used extensively to explain how people cope with personal threats ${ }^{24}$, in particular healthy eating behaviours ${ }^{52,53}$ and environmental actions to deal with climate change $\mathrm{e}^{23,54,55,56,57}$. The TPB and PMT are similar since they are both based on individual factors, yet they differ, especially since PMT has a specific risk focus ${ }^{55}$. We considered these two theories complementary in this study since they capture different dimensions of diet change behaviour at the individual and social level.

The TPB distinguishes between behavioural intention and actual behaviour. This distinction is important in the pro-environmental behaviour context, since intentions often do not yield the desired impact on environmental factors such as energy use and carbon footprint ${ }^{58,59}$. Behavioural intentions are formed by perceived behavioural control, or self-efficacy, which refers to the difficulty of performing a behaviour as perceived by the individual; subjective norms, which refers to individuals' perception of how widely the behaviour is accepted or followed in society; and attitude towards the behaviour, which refers to whether the suggested behaviour is evaluated positively or not.

According to the PMT, actions are determined by people's threat appraisal and coping appraisal. Threat appraisal is an individual assessment of the probability and severity of a threat, whereas coping appraisal refers to the extent to which an individual can and is willing to cope with the threat. Therefore, the coping appraisal is driven by self-efficacy, response efficacy, i.e. the belief whether the action will make an impact or not, and response cost, which is the cost of action in terms of time, finances, effort, etc.

Several empirical studies support the frameworks of the TPB and PMT for environmental actions and for diet change. For instance, people's eating behaviour is heavily influenced by social norms, while information about the eating behaviours of similar others or desired groups has the most powerful influence ${ }^{60}$. In-group norms and goals determine the environmental appraisals and actions of individuals in this group ${ }^{61}$. Regarding threat appraisal, the perceived threat of climate events, either to self or others such as impoverished nations, is significant enough to alter the meat consumption of individual ${ }^{62}$. Self-efficacy and response efficacy are even more significant to influence meat consumption behaviour, while response cost has no substantial effect ${ }^{62}$. Environmental self-identity is a key indicator of meat consumption, although the most important factor is income for other environmental impacts such as energy use or carbon footprint ${ }^{58}$. Supporting the threat appraisal effect, citizens with more experience of disasters have a greater willingness to pay for climate change mitigation ${ }^{63}$. 
Demographic factors also play an important role in diet change. Moser and Kleinhückelkotten ${ }^{58}$ found that gender is the most influential factor on meat consumption, as women have a stronger environmental self-identity and consume significantly less meat than men. Alló and Loureiro ${ }^{63}$ state that women are more egalitarian than men, and hence more willing to adopt climate change mitigation actions. Therefore, we aggregated such gender differences in intrinsic, identitydriven motivation in the self-efficacy multiplier in the model, which represents an individual's belief that she can easily take action. Age is an important factor that affects the social transmission mechanism. As younger people are more susceptible to peer influence ${ }^{64,65}$, the effect of norms on their behaviour is higher than the effect on older people.

\section{Model specification}

The psychological framework was adjusted to a population-level mechanism with a public segmentation and innovation diffusion approach ${ }^{32,33,66}$. The two main population segments are Meat-based Diet Followers, in other words, those who are potential adopters of a vegetarian diet, and Vegetarians. Supplementary Figure 1 visualizes the model structure with these two population segments, the flows between them, and the drivers of these flows. These two population segments are formulated as stock variables accumulating over time. The rate of Shift from vegetarianism to meat-eating, i.e. the flow from vegetarians to meat-eaters is a fraction of the Vegetarians, where this fraction is dependent on the Gross World Product (GWP) per capita. This mechanism represents the global increase in meat consumption, especially in developing countries, as the income level rises. The function $f_{\text {incomemeat }}$ is calibrated according to the historical relation between GWP and meat consumption (Supplementary Figure 2).

$$
\text { Shift from vegetarianism to meat eating }=\text { Vegetarians } * f_{\text {income,meat }}(\text { GWP per Capita })
$$

The shift from meat-eating to a vegetarian diet (Equation 2) represents 'behaviour' and depends on the intention as well as response efficacy and self-efficacy (Equation 3). While response efficacy and self-efficacy are assumed to be exogenous, response cost is excluded from the model due to its negligible role in diet change ${ }^{62}$. The behavioural intention, namely Fraction intended to change diet, is formulated as the multiplication of two factors that represent the attitude and subjective norms (Equation 4). The multiplicative formulation represents the amplifying effect of social norms, and the limited scale of attitude-dependent diet change without a high social norm effect. The Subjective norm multiplier is formulated as a logistic function of the Descriptive social norm $\left(x_{\text {norm }}\right)$, which is the fraction of Vegetarians in the total population. This logistic function (Equation 5) captures the phenomenon that the impact of norms on individuals is relatively low when the ratio of vegetarians in the total population is low, yet it increases rapidly in response to an increasing ratio of vegetarians and then stabilizes even though the vegetarian ratio is very high. $\mathrm{L}, \mathrm{k}$, and $\mathrm{x} 0$ represent the maximum value, steepness and inflection point of this logistic curve, respectively. Different parameterizations of this function form (Supplementary Figure 3) represent the age effect on the adoption of social norms.

The Attitude multiplier for diet change is the average of climate and health risk multipliers (Equation 6). Each of these risk-induced attitude multipliers are also formulated as a logistic 
function. The Climate risk multiplier is a function of the number of climate events in public memory (Supplementary Figure 4), with the assumption that a low number of climate events in the memory do not lead to a high pro-vegetarianism attitude, yet this attitude increases rapidly as the number of such events increases. This function form between risk and attitude is shown to create the highest sensitivity in global temperature change in the context of emission behaviour $^{23}$; hence it was chosen in this study. Equation 7 denotes the formulation of the climate risk multiplier with the parameters $\mathrm{L}, \mathrm{k}$ and $\mathrm{x} 0$, which represent the maximum value, steepness and inflection point of the curve respectively. The variable input of this function, $x_{\text {climate }}$, is the ratio of climate events in memory to its value in 2010 (Equation 8). This normalization with respect to the 2010 values is to have a common reference point for the calibration of social norm, climate risk, and health risk effects on diet shift.

Shift from meat eating to vegetarianism $=$ Meat based diet followers $*$ Shift fraction of meat eaters

Shift fraction of meat eaters $=$ Fractionintended to change diet $*$

\section{Self efficacymultiplier* \\ Response efficacy multiplier}

Fraction intended to change diet $=$ Normal fraction intended to change diet $*$

Subjective norm multiplier *

Attitude multiplier for diet change

Subjective norm multiplier $=\frac{L_{\text {norm }}}{1+e^{-k_{\text {norm }} *\left(x_{\text {norm }}(t)-x 0_{\text {norm }}\right)}}$

Attitude multiplier for diet change $=($ Climate risk multiplier + Health risk multiplier $) / 2$

$$
\begin{gathered}
\text { Climate risk multiplier }(t)=\frac{L_{\text {climate }}}{1+e^{-k_{\text {climate }} *\left(x_{\text {climate }}(t)-x 0_{\text {climate }}\right)}} \\
x_{\text {climate }}(t)=\frac{\text { Climate events in memory }(t)}{\text { Climate events in memory }(2010)}
\end{gathered}
$$

Similarly, the Health risk multiplier is a logistic function of perceived health risk (Equation 9 and Supplementary Figure 5). Risk perception that triggers healthy eating behaviour is most related to the objective health parameters individuals experience ${ }^{67}$, such as blood sugar- and cholesterol levels. At the population level, the annual number of deaths attributed to red meat consumption is considered a proxy for perceived health risk (Equation 10). Moreover, death rates related to red meat also trigger a more widespread communication, reinforcing its role as a proxy for the perceived health risk. In the model, the number of deaths attributed to high red meat consumption was formulated endogenously as a function of the cumulative red meat consumption of the meat-based diet followers, not the entire population. The choice to consider cumulative red meat consumption instead of annual consumption was to include the effects of long-term consumption. This function was calibrated in a linear form for the age cohorts between 25 and 44, and in a logistic form for the other cohorts, following the data patterns in the period 1990-2017 reported by the Global Burden of Disease Study ${ }^{68}$. Supplementary Figures 6 and 7 show the model functions and the data for red meat consumption and the related deaths, while Supplementary Table 2 presents the parameter values of the model functions. 


$$
\begin{gathered}
\text { Health risk multiplier }(t)=\frac{L_{\text {health }}}{1+e^{-k_{\text {hadh }} *\left(x_{\text {healh }}(t)-x 0_{\text {hachl }}\right)}} \\
x_{\text {health }}(t)=\frac{\text { Deaths related to red meat }(t)}{\text { Deaths related to red meat }(2010)}
\end{gathered}
$$

1 Further explanation of model specification can be found in Supplementary Methods, which

2 particularly explain

- how demographic heterogeneity is included in the model,

- compositions of different diet types and how the global food demand is calculated based on them,

- how extreme climate events and the public memory of them is modelled.

\section{Parameterization and validation}

This model of diet shift mechanisms heavily depends on the global number of vegetarians and meat-based diet followers, as well as on socio-psychological parameters that cannot be quantified straightforwardly. However, data availability about the global vegetarian population or similar demographic factors is considerably limited. The literature, if available, provides quantitative measures on an ordinal scale for the socio-psychological parameters, yet they do not precisely correspond to the model definitions. For instance, the relative contribution of selfefficacy, response-efficacy, and risk perception to diet change behaviour can be inferred ${ }^{53,67}$. However, for the social norm, climate risk, and health risk multipliers, only the function forms ${ }^{23}$ and the difference between age and education groups could be qualitatively estimated.

Therefore, we quantified the model in three complementary ways: (i) Initialization based on the estimate that there were approximately 1.5 billion $\left(21.5 \%\right.$ ) vegetarians in the world in $2010^{69}$; (ii) calibration of behavioural parameters according to the historical consumption of various food categories, and according to a reference simulation with an increasing vegetarian population due to increasing awareness in the western world, and (iii) empirical studies that indicate the relative values of the psychological parameters (e.g., the self-efficacy of women and men). In other words, we found the parameter values that minimize the difference between the historical data and model values of food consumption in step (ii). In step (iii), we checked if the relative calibrated values coincide with the qualitative information in the literature and reiterated the calibration if not.

The parameter values obtained from the calibration procedure (Supplementary Table 3), however, are still highly uncertain, because they are calibrated according to variables that they are not directly linked to, and because multiple sets of parameter combinations could match the historical data. This is the reason for following an uncertainty-focused approach in this study rather than providing best-estimate projections, for using the model to explore various assumptions and for identifying the most influential of these uncertain parameters.

The approaches to and perspectives on validation differ across different modelling fields ${ }^{70}$. In this study, we used a combination of validation approaches from management science ${ }^{71}$, and employed a historical data comparison for the food and land use sector, as well as expert reviews about psychological mechanisms. In particular, we compared the model output to 
historical data on Agricultural Land, Forest Land and Food Supply (Supplementary Figure 9), which are directly affected by the food demand induced by diet shifts. We also cross-validate the model with the output of an established land use model, the Global Biosphere Management Model (GLOBIOM) ${ }^{72}$.

\section{Global Sensitivity Analysis and Sobol indices}

Global Sensitivity Analysis (GSA) ${ }^{73,74}$ is a standard method for evaluating the impact of uncertain inputs of complex environmental models. GSA is a multivariate analysis where the importance of each input is computed in interaction with all other inputs, which makes it suitable for complex models that include a large number of highly uncertain inputs and their nonlinear relationships. There are several techniques used in GSA applications. Variance-based Sobol indices represent the contribution of each uncertain model parameter to the output variance $^{75}$, yet they are computationally intense. Decision tree-based ones alleviate computational intensity ${ }^{76}$, yet sacrifice precision. We choose to use Sobol indices in this study to identify the most influential uncertain inputs, because they indicate the sensitivity caused by a parameter regardless of the initial parameterization of the model.

GSA applications often distinguish between the first-order and total Sobol indices ${ }^{75}$. The first order Sobol sensitivity index $\left(\mathrm{S}_{1, \mathrm{i}}\right)$ is the fraction of the total variance attributed only to an individual input factor $X_{i}$, while the total Sobol sensitivity index $\left(\mathrm{S}_{\mathrm{T}, \mathrm{i}}\right)$ refers to the fraction of variance attributed to an input factor and its interactions with all other factors. Therefore, while $\mathrm{S}_{1, \mathrm{i}}$ provides an isolated measure of sensitivity to the input factor $X_{i}, \mathrm{~S}_{\mathrm{T}, \mathrm{i}}$ gives an account of the sensitivity to a parameter's overall role in the output. Equations 11 denotes $S_{1, \text { i, }}$ where $V[Y]$ is the unconditional variance of model variable $\mathrm{Y}$ and $V_{i}$ is the variance of the conditional mean of $\mathrm{Y}$ when the parameter $\mathrm{X}_{\mathrm{i}}$ is fixed within its range. Similarly, Equation 12 denotes $\mathrm{S}_{\mathrm{T}, \mathrm{i}}$, where $V_{\sim i}$ is the variance of the conditional mean of $\mathrm{Y}$ when all factors except $X_{i}$ are fixed. In this study, we calculated both $S_{1}$ and $S_{T}$ to investigate the individual and interaction effects of behavioural parameters on diet change.

$$
\begin{gathered}
S_{1, i}=\frac{V_{i}}{V[Y]}=\frac{V\left[E\left(Y / X_{i}\right)\right]}{V[Y]} \\
S_{T, i}=\frac{V_{\sim i}}{V[Y]}=\frac{V\left[E\left(Y / X_{\sim i}\right)\right]}{V[Y]}
\end{gathered}
$$

We calculated the Sobol indices using the Python SALib library ${ }^{77}$ which implements a sampling design generated to compute the unconditional variance of the output based on Monte Carlo simulations $^{78}$. This sampling method requires $N=n(2 p+2)$ experiments, where $n$ is the number of simulations and $p$ is the number of uncertain inputs. Rozen and Kwakkel ${ }^{76}$ show that Sobol indices stabilize after $\mathrm{N}>150,000$ experiments for a model with 19 parameters, and after $\mathrm{N}>9 \mathrm{e}+6$ experiments for a model with 31 parameters. For our model with 36 parameters, we reported the results of $\mathrm{N}=185,000$ experiments because the ranking of the parameters stabilizes at this $\mathrm{N}$ value (Supplementary Figure 10).

The sensitivity of dynamic models can demonstrate significant differences over time, as exemplified in the case of climate change abatement pathways ${ }^{79}$. To account for the potential 
differences in sensitivity results caused by dynamics over time, as well as different diet composition scenarios, we calculated the sensitivity indices for each diet composition scenario separately and at two time points, 2050 and 2100. In other words, we calculated eight sets of Sobol sensitivity indices, based on $\mathrm{N}=185,000$ simulation experiments for each diet composition scenario. Supplementary Figures 11-13 show the results of each set except Scenario 0, while the main text synthesizes the overall findings.

\section{Scenario discovery with the Patient Rule Induction Method (PRIM)}

Computational scenario discovery is an approach increasingly used to identify the uncertainties that lead to particular outcomes of interest in large scenario ensembles ${ }^{35,80,81}$. It is implemented using various data mining algorithms, such as Classification and Regression Trees (CART) ${ }^{82}$ and Patient Rule Induction Method (PRIM) ${ }^{36,83,84,85}$. PRIM aims to find the subspaces of the uncertainty space, that is, combinations of uncertain input values that lead to predefined regions of the outcome space. These outcomes are called cases of interest, and the resulting uncertainty subspaces distinguish them from the rest. Uncertainty subspaces are described as hyper rectangular boxes, and each box has three important attributes. Density is the ratio of cases of interest in a box to the total number of cases in that box, whereas coverage is the ratio of the cases of interest in a box to the total cases of interest in the entire scenario space.

Interpretability refers to the ease of understanding and insightfulness of a scenario defined by a box, and it is measured by the maximum number of restricted dimensions, that is, input parameters. A box with a high density, coverage and interpretability would yield ideal results, yet there is often a trade-off between the accuracy provided by a high density and inclusiveness provided by a high coverage ${ }^{35}$. Therefore, multiple boxes should be examined to reach consistent and insightful conclusions.

In this study, we used the PRIM implementation in the Python library EMA Workbench ${ }^{86}$. Alongside the coverage, density and interpretability values of each box, this PRIM implementation reports quasi $\mathrm{p}$-values for the likelihood that a parameter is constrained by coincidence. These $\mathrm{p}$-values result from a quasi p-test described by Bryant and Lempert ${ }^{35}$, where the null hypothesis is that the contribution of a restricted parameter to the box is negligible compared to the contribution of all other restricted parameters in that box. Therefore, small p-values reject the null hypothesis and imply that a parameter is identified not by coincidence but with relative confidence.

We ran the PRIM algorithm on a dataset of 40,000 simulations, 10,000 for each diet composition scenario created by Latin Hypercube Sampling. To accommodate the differences in dynamics over time we repeated the analysis for two time points, 2050 and 2100. At each time point, we defined the cases of interest as those where the Percentage of Vegetarians is higher than the $3^{\text {rd }}$ quartile of its values across the scenario space. This corresponds to the simulations, for instance, where the vegetarian fraction is higher than $22.1 \%$ and $21.2 \%$ in 2050 in the reference and the third diet composition scenarios, respectively (Fig. 3). The boxes identified in each execution of the PRIM algorithm show an almost linear trade-off between coverage and density (Supplementary Figure 14), indicating that coverage has to be sacrificed for the 
1 precision provided by density or vice versa. Therefore, we examined different PRIM boxes

2 (Supplementary Figure 15-18) and reported the ones with a high density but low coverage (

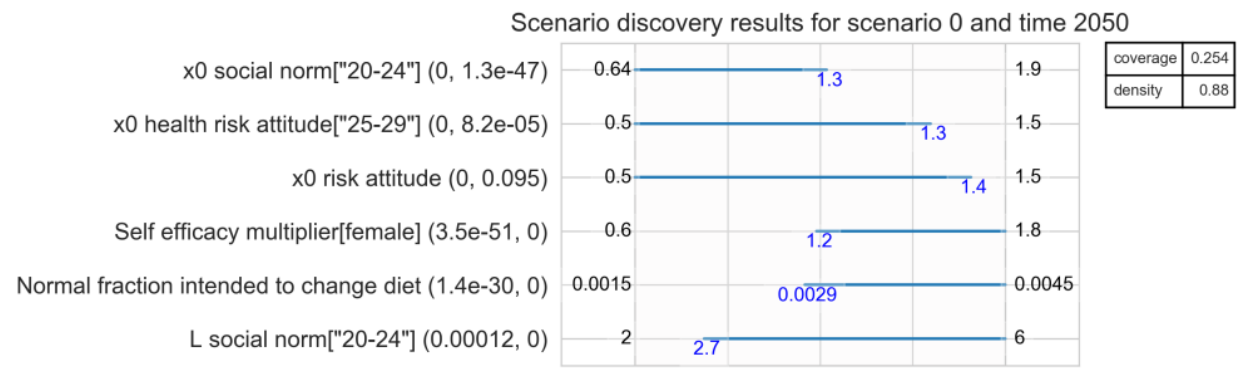

(a)

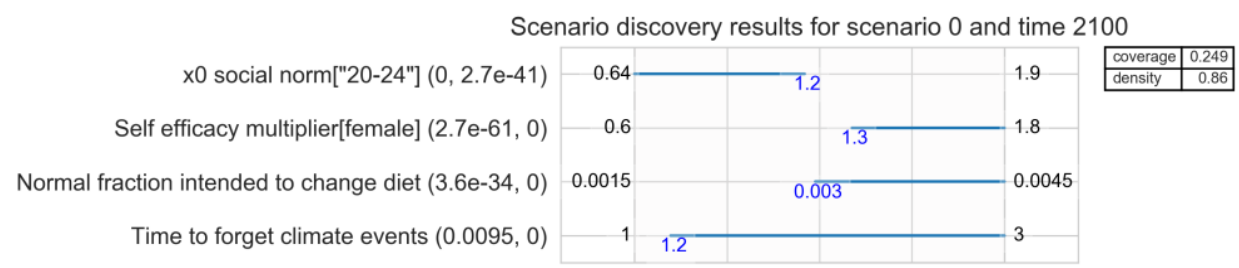

(b)

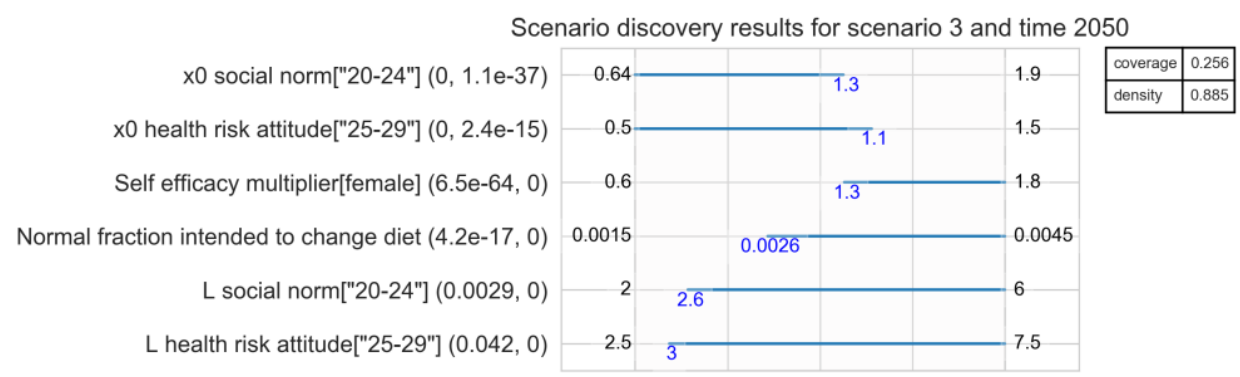

(c)

3 Fig. 5). The reason for this choice to report high density boxes was the higher number of restricted parameters they include, and thus the wider variety of insights they lead to about the important behavioural factors behind diet change. Still, we presented a summary of the findings

6 from different PRIM boxes and discussed the overall factors that distinguish the scenarios with

7 widespread diet shifts.

\section{Data Availability}

9 The input data of the model presented in this study can be seen in Supplementary Table 3. The

10 input data are obtained from calibration according to historical data of agro-economic variables

11 as described in Methods. The historical data used in calibration is obtained from the statistics of

12 the United Nations Food and Agriculture Organization, available at

13 http://www.fao.org/faostat/en/\#data. This study also made use of online Global Burden of

14 Disease datasets (http://ghdx.healthdata.org) provided by the Institute for Health Metrics and

15 Evaluation, University of Washington. 


\section{Code Availability}

The model used in this study (the FeliX Model), as well as its input data is available on https://github.com/iiasa/Felix-Model/tree/master/Current\%20Version. The custom computer code written in Python (IPython Notebooks) and used to analyse simulation results can be accessed on https://github.com/sibeleker/FeliX DietChange.

\section{References}

1. Creutzig F, Roy J, Lamb WF, Azevedo IML, Bruine de Bruin W, Dalkmann H, et al. Towards demand-side solutions for mitigating climate change. Nature Climate Change 2018, 8(4): 260-263.

2. Steg L. Limiting climate change requires research on climate action. Nature Climate Change 2018, 8(9): 759-761.

3. Rogelj J, Shindell D, Jiang K, Fifita S, Forster P, Ginzburg V, et al. Mitigation pathways compatible with $1.5^{\circ} \mathrm{C}$ in the context of sustainable development. In: V. Masson-Delmotte PZ, H. O. Pörtner, D. Roberts, J. Skea, P.R. Shukla, A. Pirani, W. Moufouma-Okia, C. Péan, R. Pidcock, S. Connors, J. B. R. Matthews, Y. Chen, X. Zhou, M. I. Gomis, E. Lonnoy, T. Maycock, M. Tignor, T. Waterfield (ed). Global warming of $1.5^{\circ} \mathrm{C}$. An IPCC Special Report on the impacts of global warming of $1.5^{\circ} \mathrm{C}$ above pre-industrial levels and related global greenhouse gas emission pathways, in the context of strengthening the global response to the threat of climate change, sustainable development, and efforts to eradicate poverty In Press, 2018.

4. Grubler A, Wilson C, Bento N, Boza-Kiss B, Krey V, McCollum DL, et al. A low energy demand scenario for meeting the $1.5^{\circ} \mathrm{C}$ target and sustainable development goals without negative emission technologies. Nature Energy 2018, 3(6): 515-527.

5. Foley JA, Ramankutty N, Brauman KA, Cassidy ES, Gerber JS, Johnston M, et al. Solutions for a cultivated planet. Nature 2011, 478(7369): 337-342.

6. Rockström J, Steffen W, Noone K, Persson Å, Chapin III FS, Lambin EF, et al. A safe operating space for humanity. Nature 2009, 461(7263): 472. 
7. Steffen W, Richardson K, Rockström J, Cornell SE, Fetzer I, Bennett EM, et al. Planetary boundaries: Guiding human development on a changing planet. Science 2015, 347(6223): 1259855.

8. Stehfest E, Bouwman L, Van Vuuren DP, Den Elzen MG, Eickhout B, Kabat P. Climate benefits of changing diet. Climatic change 2009, 95(1-2): 83-102.

9. Popp A, Lotze-Campen H, Bodirsky B. Food consumption, diet shifts and associated non- $\mathrm{CO} 2$ greenhouse gases from agricultural production. Global Environmental Change 2010, 20(3): 451-462.

10. Tilman D, Clark M. Global diets link environmental sustainability and human health. Nature 2014, 515(7528): 518.

11. Obersteiner M, Walsh B, Frank S, Havlík P, Cantele M, Liu J, et al. Assessing the land resource-food price nexus of the Sustainable Development Goals. Science Advances 2016, 2(9).

12. Springmann M, Clark M, Mason-D'Croz D, Wiebe K, Bodirsky BL, Lassaletta $\mathrm{L}$, et al. Options for keeping the food system within environmental limits. Nature 2018, 562(7728): 519-525.

13. FAO. Food Balance Sheets. Food and Agriculture Organization of the United Nations; 2018.

14. Waitrose and Partners. Food and Drink Report: The Era of the Mindful Consumer; 2018.

15. De Boer J, Schösler H, Boersema JJ. Climate change and meat eating: an inconvenient couple? Journal of Environmental Psychology 2013, 33: 1-8.

16. Macdiarmid JI, Douglas F, Campbell J. Eating like there's no tomorrow: Public awareness of the environmental impact of food and reluctance to eat less meat as part of a sustainable diet. Appetite 2016, 96: 487-493.

17. Dhont K, Hodson G. Why do right-wing adherents engage in more animal exploitation and meat consumption? Personality and Individual Differences 2014, 64: 12-17. 
18. Dhont K, Hodson G, Leite AC. Common ideological roots of speciesism and generalized ethnic prejudice: The social dominance human-animal relations model (SD-HARM). European Journal of Personality 2016, 30(6): 507-522.

19. Hodson G, Earle M. Conservatism predicts lapses from vegetarian/vegan diets to meat consumption (through lower social justice concerns and social support). Appetite 2018, 120: 75-81.

20. Rydzak F, Obersteiner M, Kraxner F, Fritz S, McCallum I. FeliX3 - Impact Assessment Model: Systemic view across Societal Benefit Areas beyond Global Earth Observation. Laxenburg: International Institute for Applied Systems Analysis (IIASA); 2013.

21. Walsh BJ, Rydzak F, Palazzo A, Kraxner F, Herrero M, Schenk PM, et al. New feed sources key to ambitious climate targets. Carbon balance and management 2015, 10(1): 26.

22. Walsh B, Ciais P, Janssens IA, Peñuelas J, Riahi K, Rydzak F, et al. Pathways for balancing CO2 emissions and sinks. Nature Communications 2017, 8: 14856.

23. Beckage B, Gross LJ, Lacasse K, Carr E, Metcalf SS, Winter JM, et al. Linking models of human behaviour and climate alters projected climate change. Nature Climate Change 2018: 1.

24. Ajzen I. The theory of planned behavior. Organizational Behavior and Human Decision Processes 1991, 50(2): 179-211.

25. Boer H, Seydel ER. Protection motivation theory. In: Conner M, Norman P (eds). Predicting health behaviour: Research and practice with social cognition models. Open University Press: Maidenhead, BRK, England, 1996.

26. Slovic P. Perception of risk. Science 1987, 236(4799): 280-285.

27. Fox N, Ward K. Health, ethics and environment: a qualitative study of vegetarian motivations. Appetite 2008, 50(2-3): 422-429.

28. Stehfest E. Food choices for health and planet. Nature 2014, 515: 501. 
29. Westhoek H, Lesschen JP, Rood T, Wagner S, De Marco A, Murphy-Bokern D, et al. Food choices, health and environment: Effects of cutting Europe's meat and dairy intake. Global Environmental Change 2014, 26: 196-205.

30. Springmann M, Godfray HCJ, Rayner M, Scarborough P. Analysis and valuation of the health and climate change cobenefits of dietary change. Proceedings of the National Academy of Sciences 2016, 113(15): 4146-4151.

31. Willett W, Rockström J, Loken B, Springmann M, Lang T, Vermeulen S, et al. Food in the Anthropocene: the EAT-Lancet Commission on healthy diets from sustainable food systems; 2019. Report No.: 0140-6736.

32. Rogers EM. Diffusion of innovations. Simon and Schuster, 2010.

33. Bass FM. A new product growth for model consumer durables. Management Science 1969, 15(5): 215-227.

34. Vranken L, Avermaete T, Petalios D, Mathijs E. Curbing global meat consumption: Emerging evidence of a second nutrition transition. Environmental Science \& Policy 2014, 39: 95-106.

35. Bryant BP, Lempert RJ. Thinking inside the box: a participatory, computerassisted approach to scenario discovery. Technological Forecasting and Social Change 2010, 77(1): 34-49.

36. Kwakkel JH, Jaxa-Rozen M. Improving scenario discovery for handling heterogeneous uncertainties and multinomial classified outcomes. Environmental Modelling \& Software 2016, 79: 311-321.

37. Hayhoe K. When facts are not enough. Science 2018, 360(6392): 943-943.

38. Kahan D. Fixing the communications failure. Nature 2010, 463(7279): 296.

39. Kahan DM, Peters E, Wittlin M, Slovic P, Ouellette LL, Braman D, et al. The polarizing impact of science literacy and numeracy on perceived climate change risks. Nature climate change 2012, 2(10): 732. 
40. Fielding KS, McDonald R, Louis WR. Theory of planned behaviour, identity and intentions to engage in environmental activism. Journal of environmental psychology 2008, 28(4): 318-326.

41. Nigbur D, Lyons E, Uzzell D. Attitudes, norms, identity and environmental behaviour: Using an expanded theory of planned behaviour to predict participation in a kerbside recycling programme. British Journal of Social Psychology 2010, 49(2): 259-284.

42. Gatersleben B, Murtagh N, Abrahamse W. Values, identity and proenvironmental behaviour. Contemporary Social Science 2014, 9(4): 374-392.

43. Fanghella V, d'Adda G, Tavoni M. On the Use of Nudges to Affect Spillovers in Environmental Behaviors. Frontiers in Psychology 2019, 10(61).

44. Reese G, Junge E. Keep on rockin'in a (plastic-) free world: Collective efficacy and pro-environmental intentions as a function of task difficulty. Sustainability 2017, 9(2): 200 .

45. Jugert P, Greenaway KH, Barth M, Büchner R, Eisentraut S, Fritsche I. Collective efficacy increases pro-environmental intentions through increasing self-efficacy. Journal of Environmental Psychology 2016, 48: 12-23.

46. Pohjolainen P, Vinnari M, Jokinen P. Consumers' perceived barriers to following a plant-based diet. British Food Journal 2015, 117(3): 1150-1167.

47. McCollum DL, Wilson C, Pettifor H, Ramea K, Krey V, Riahi K, et al. Improving the behavioral realism of global integrated assessment models: An application to consumers' vehicle choices. Transportation Research Part D: Transport and Environment 2017, 55: 322-342.

48. Pettifor H, Wilson C, McCollum D, Edelenbosch OY. Modelling social influence and cultural variation in global low-carbon vehicle transitions. Global Environmental Change 2017, 47: 76-87.

49. Rydzak F, Obersteiner M, Kraxner F. Impact of Global Earth ObservationSystemic view across GEOSS societal benefit area. International Journal of Spatial Data Infrastructures Research 2010: 216-243. 
50. Obersteiner M, Rydzak F, Fritz S, McCallum I. Valuing the potential impacts of GEOSS: a systems dynamics approach. The Value of Information. Springer, 2012, pp 67-90.

51. Rogers RW. A protection motivation theory of fear appeals and attitude change1. The journal of psychology 1975, 91(1): 93-114.

52. Povey R, Conner M, Sparks P, James R, Shepherd R. The theory of planned behaviour and healthy eating: Examining additive and moderating effects of social influence variables. Psychology \& Health 2000, 14(6): 991-1006.

53. de Ridder D, Kroese F, Evers C, Adriaanse M, Gillebaart M. Healthy diet: Health impact, prevalence, correlates, and interventions. Psychology \& health 2017, 32(8): 907-941.

54. Tikir A, Lehmann B. Climate change, theory of planned behavior and values: a structural equation model with mediation analysis. Climatic change 2011, 104(2): 389-402.

55. Bockarjova M, Steg L. Can Protection Motivation Theory predict proenvironmental behavior? Explaining the adoption of electric vehicles in the Netherlands. Global Environmental Change 2014, 28: 276-288.

56. Aerts JCJH, Botzen WJ, Clarke KC, Cutter SL, Hall JW, Merz B, et al. Integrating human behaviour dynamics into flood disaster risk assessment. Nature Climate Change 2018, 8(3): 193-199.

57. Renger D, Reese G. From equality-based respect to environmental activism: Antecedents and consequences of global identity. Political Psychology 2017, 38(5): 867-879.

58. Moser S, Kleinhückelkotten S. Good Intents, but Low Impacts: Diverging Importance of Motivational and Socioeconomic Determinants Explaining ProEnvironmental Behavior, Energy Use, and Carbon Footprint. Environment and behavior 2017: 0013916517710685.

59. Bamberg S, Möser G. Twenty years after Hines, Hungerford, and Tomera: A new meta-analysis of psycho-social determinants of pro-environmental behaviour. Journal of environmental psychology 2007, 27(1): 14-25. 
60. Robinson E, Thomas J, Aveyard P, Higgs S. What everyone else is eating: a systematic review and meta-analysis of the effect of informational eating norms on eating behavior. Journal of the Academy of Nutrition and Dietetics 2014, 114(3): 414-429.

61. Fritsche I, Barth M, Jugert P, Masson T, Reese G. A Social Identity Model of Pro-Environmental Action (SIMPEA). Psychological Review 2018, 125: 245 269.

62. Hunter E, Röös E. Fear of climate change consequences and predictors of intentions to alter meat consumption. Food Policy 2016, 62: 151-160.

63. Alló M, Loureiro ML. The role of social norms on preferences towards climate change policies: A meta-analysis. Energy Policy 2014, 73: 563-574.

64. Steinberg L, Monahan KC. Age Differences in Resistance to Peer Influence. Developmental psychology 2007, 43(6): 1531-1543.

65. Knoll LJ, Leung JT, Foulkes L, Blakemore S-J. Age-related differences in social influence on risk perception depend on the direction of influence. Journal of Adolescence 2017, 60: 53-63.

66. Sterman JD. Business Dynamics: Systems Thinking and Modeling for a Complex World. Irwin/McGraw-Hill: Boston, 2000.

67. Renner B, Schwarzer R. The motivation to eat a healthy diet: How intenders and nonintenders differ in terms of risk perception, outcome expectancies, selfefficacy, and nutrition behavior. Polish Psychological Bulletin 2005, 36(1): 715.

68. GHDx. Global Burden of Disease Study 2017. Seattle, USA: University of Washington; 2019.

69. Leahy E, Lyons S, Tol RS. An estimate of the number of vegetarians in the world: ESRI working paper; 2010. 
70. Eker S, Rovenskaya E, Obersteiner M, Langan S. Practice and perspectives in the validation of resource management models. Nature Communications 2018, 9(1): 5359.

71. Barlas Y. Formal aspects of model validity and validation in system dynamics. System Dynamics Review 1996, 12(3): 183-210.

72. Valin H, Havlík P, Forsell N, Frank S, Mosnier A, Peters D, et al. Description of the GLOBIOM (IIASA) model and comparison with the MIRAGE-BioF (IFPRI) model. Crops 2013, 8: 3.1.

73. Saltelli A, Ratto M, Andres T, Campolongo F, Cariboni J, Gatelli D, et al. Global sensitivity analysis: the primer. John Wiley \& Sons, 2008.

74. Saltelli A, Annoni P, Azzini I, Campolongo F, Ratto M, Tarantola S. Variance based sensitivity analysis of model output. Design and estimator for the total sensitivity index. Computer Physics Communications 2010, 181(2): 259-270.

75. Sobol IM. Global sensitivity indices for nonlinear mathematical models and their Monte Carlo estimates. Mathematics and computers in simulation 2001, 55(1-3): 271-280.

76. Jaxa-Rozen M, Kwakkel J. Tree-based ensemble methods for sensitivity analysis of environmental models: A performance comparison with Sobol and Morris techniques. Environmental Modelling \& Software 2018.

77. Herman J, Usher W. SALib: an open-source Python library for sensitivity analysis. The Journal of Open Source Software 2017, 2(9).

78. Saltelli A. Making best use of model evaluations to compute sensitivity indices. Computer physics communications 2002, 145(2): 280-297.

79. Lamontagne JR, Reed PM, Marangoni G, Keller K, Garner GG. Robust abatement pathways to tolerable climate futures require immediate global action. Nature Climate Change 2019, 9(4): 290-294.

80. Lempert RJ, Groves DG, Popper SW, Bankes SC. A general, analytic method for generating robust strategies and narrative scenarios. Management science 2006, 52(4): 514-528. 
81. Lempert RJ, Bryant BP, Bankes SC. Comparing algorithms for scenario discovery. RAND, Santa Monica, CA 2008.

82. Lamontagne JR, Reed PM, Link R, Calvin KV, Clarke LE, Edmonds JA. Large Ensemble Analytic Framework for Consequence-Driven Discovery of Climate Change Scenarios. Earth's Future 2018, 6(3): 488-504.

83. Rozenberg J, Guivarch C, Lempert R, Hallegatte S. Building SSPs for climate policy analysis: a scenario elicitation methodology to map the space of possible future challenges to mitigation and adaptation. Climatic change 2014, 122(3): 509-522.

84. Guivarch C, Rozenberg J, Schweizer V. The diversity of socio-economic pathways and $\mathrm{CO} 2$ emissions scenarios: insights from the investigation of a scenarios database. Environmental Modelling \& Software 2016, 80: 336-353.

85. Eker S, van Daalen E. A model-based analysis of biomethane production in the Netherlands and the effectiveness of the subsidization policy under uncertainty. Energy Policy 2015, 82: 178-196.

86. Kwakkel JH. The Exploratory Modeling Workbench: An open source toolkit for exploratory modeling, scenario discovery, and (multi-objective) robust decision making. Environmental Modelling \& Software 2017, 96: 239-250.

\section{Acknowledgements}

This research was supported by the International Institute for Applied Systems Analysis (IIASA) and by the European Research Council Synergy grant ERC-2013-SyG. 610028IMBALANCE-P. We thank Hugo Valin for his suggestion to use the Global Burden of Disease datasets model the health risk of red meat consumption. We thank Ansa Heyl for language check.

\section{Contributions}

S.E. designed the research; S.E., G.R. and M.O. conceptualized the model; S.E. developed the model; conducted the analysis and wrote the manuscript with contributions from G.R. and M.O. All authors contributed to the discussion and interpretation of the results. 
Eker S, Reese G, \& Obersteiner M (2019). Modelling the drivers of a widespread shift to sustainable diets. Nature Sustainability DOI:10.1038/s41893-019-0331-1

\section{Competing interests}

2 The authors declare no competing interests.

\section{Correspondence}

4 Correspondence to Sibel Eker (eker@iiasa.ac.at) 